\title{
Coping with climate variability and climate change in La Ceiba, Honduras
}

\author{
Joel B. Smith • Kenneth M. Strzepek • Julio Cardini • Mario Castaneda • \\ Julie Holland • Carlos Quiroz • Tom M. L. Wigley • Jose Herrero • Peter Hearne • \\ John Furlow
}

Received: 21 August 2008 / Accepted: 18 May 2011 / Published online: 9 August 2011

(C) Springer Science+Business Media B.V. 2011

\begin{abstract}
La Ceiba, Honduras, a city of about 200,000 people, lies along the Caribbean Sea, nestled against a mountain range and the Rio Cangrejal. The city faces three flooding risks: routine flooding of city streets due to the lack of a stormwater drainage system; occasional major flooding of the Rio Cangrejal, which flows through the city; and flooding from heavy rainfall events and storm surges associated with tropical cyclones. In this study, we applied a method developed for the U.S. Agency for
\end{abstract}

\section{J. B. Smith $(\bowtie)$}

Stratus Consulting Inc., Boulder, CO, USA

e-mail: jsmith@stratusconsulting.com

K. M. Strzepek

Massachusetts Institute of Technology, Cambridge, MA, USA

J. Cardini

Serman \& Associates S.A. and National Technological University, Buenos Aires, Argentina

M. Castaneda

Geoscience Institute, Polytechnical University of Engineering (UPI), Tegucigalpa, Honduras

J. Holland

ABPmer, Southampton, UK

C. Quiroz

Colorado State University, Fort Collins, CO, USA

T. M. L. Wigley

National Center for Atmospheric Research, Boulder, CO, USA

J. Herrero

Fundacion Cuero y Salado, La Ceiba, Honduras

P. Hearne

U.S. Agency for International Development, Tegucigalpa, Honduras

J. Furlow

U.S. Agency for International Development, Washington, DC, USA 
International Development and then worked with stakeholders in La Ceiba to understand climate change risks and evaluate adaptation alternatives. We estimated the impacts of climate change on the current flooding risks and on efforts to mitigate the flooding problems. The climate change scenarios, which addressed sea level rise and flooding, were based on the Intergovernmental Panel on Climate Change estimates of sea level rise (Houghton et al. 2001) and published literature linking changes in temperature to more intense precipitation (Trenberth et al., Bull Am Meteorol Soc, 84:1205-1217, 2003) and hurricanes (Knutson and Tuleya, J Clim, 17:3477-3495, 2004). Using information from Trenberth et al., Bull Am Meteorol Soc, 84:1205-1217, (2003) and Knutson and Tuleya, J Clim, 17:3477-3495, 2004, we scaled intense precipitation and hurricane wind speed based on projected temperature increases. We estimated the volume of precipitation in intense events to increase by 2 to $4 \%$ in 2025 and by 6 to $14 \%$ by 2050 . A $13 \%$ increase in intense precipitation, the high scenario for 2050 , could increase peak 5 -year flood flows by about $60 \%$. Building an enhanced urban drainage system that could cope with the estimated increased flooding would cost one-third more than building a system to handle current climate conditions, but would avoid costlier reconstruction in the future. The flow of the Rio Cangrejal would increase by one-third from more intense hurricanes. The costs of raising levees to protect the population from increased risks from climate change would be about $\$ 1$ million. The coast west of downtown La Ceiba is the most vulnerable to sea level rise and storm surges. It is relatively undeveloped, but is projected to have rapid development. Setbacks on coastal construction in that area may limit risks. The downtown coastline is also at risk and may need to be protected with groins and sand pumping. Stakeholders in La Ceiba concluded that addressing problems of urban drainage should be a top priority. They emphasized improved management of the Rio Cangrejal watershed and improved storm warnings to cope with risks from extreme precipitation and cyclones. Adoption of risk management principles and effective land use management could also help reduce risks from current climate and climate change.

\section{Introduction}

La Ceiba, Honduras, is quite vulnerable to floods and sea level rise because of its topography. Located in approximately the center of the north coast of Honduras (see Fig. 1), it is a low-lying city sandwiched between the Caribbean Sea to the north and the Nombre de Dios mountains to the south. The foothills to the mountains begin only a mile from the ocean, and the mountains quickly rise to $8,000 \mathrm{ft}$. The city is located in an alluvial floodplain. Figure 2 shows La Ceiba and its proximity to the Caribbean Sea, the mountains, and the Rio Cangrejal.

La Ceiba's climate is tropical. Having steep mountains close to the ocean, La Ceiba receives an average of $3.5 \mathrm{~m}$ of precipitation a year (data provided by Dole Food Company, January 18, 2010). Precipitation is at its highest from October to January, resulting from hurricanes and cold fronts from the north. Because the mountains drop quickly into the lowlying narrow plain, La Ceiba and surrounding areas are routinely subjected to flooding. Previously, much of the area was wetlands, which were filled in, as were drainages to the oceans.

The most severe climate event to hit the region in recent years was Hurricane Mitch. In late October 1998, Mitch settled over Honduras for 4 days, dumping up to nine-tenths of a meter of rain. Massive flooding, loss of life, and destruction of property resulted. About 


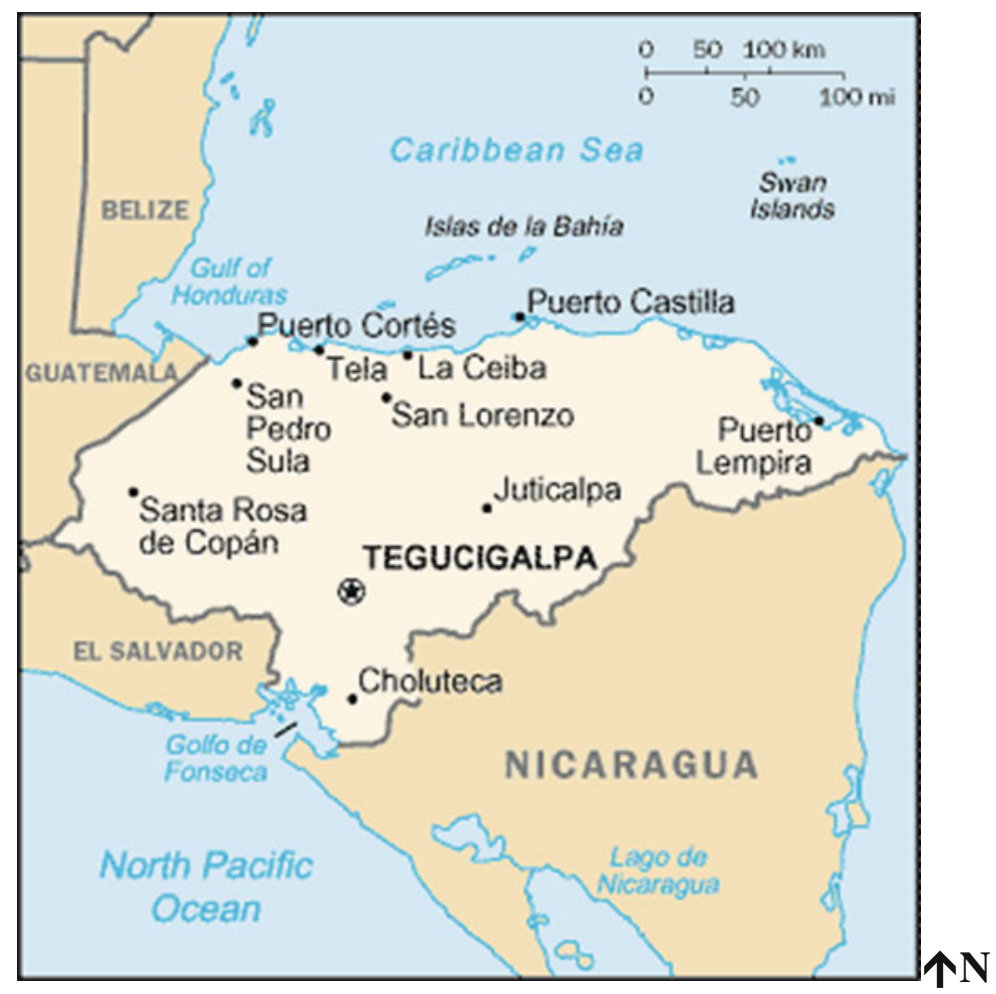

Fig. 1 Map of Honduras. Source: Gurteen Knowledge Website 2006

two-thirds of La Ceiba was flooded when the Rio Cangrejal flooded its banks and a major bridge crossing the river was destroyed. Hurricane Fifi, which moved along the north coast of Honduras in 1974, also caused serious damage. Although Mitch was the most severe storm to hit La Ceiba, the city has received more rain in other months. For example, during the first 4 weeks of 1999, La Ceiba received more than $1.5 \mathrm{~m}$ of rain.

La Ceiba is a bustling but largely poor city with a strong potential for tourism. Its origins began with the tropical fruit industry. La Ceiba was developed at the beginning of the 20th century and was used as a port by banana companies (Merrill 1995). It is a way station to the popular tourist destination of Roatan Island. In recent years, a number of maquiladoras opened in La Ceiba, employing mostly women. The city could be a tourist destination because it is located on the Caribbean and abuts the beautiful Pico Bonito National Park. This natural area, which includes the mountains described above, offers white water rafting, hiking, and bird and butterfly watching.

Honduras is a very poor country with meager resources to cope with risks from the current climate, let alone climate change. It is one of the poorest countries in Latin America (ranking the fourth poorest in the region; WRI 2005). It is apparent that the risk of destruction from natural disasters is an important impediment to development in La Ceiba and perhaps elsewhere in Honduras.

Because of its size, location, and importance for tourism and agriculture, La Ceiba has been a key development site for the last 15 years for the U.S. Agency for International Development (USAID) in Honduras. USAID has contributed significantly in the areas of 


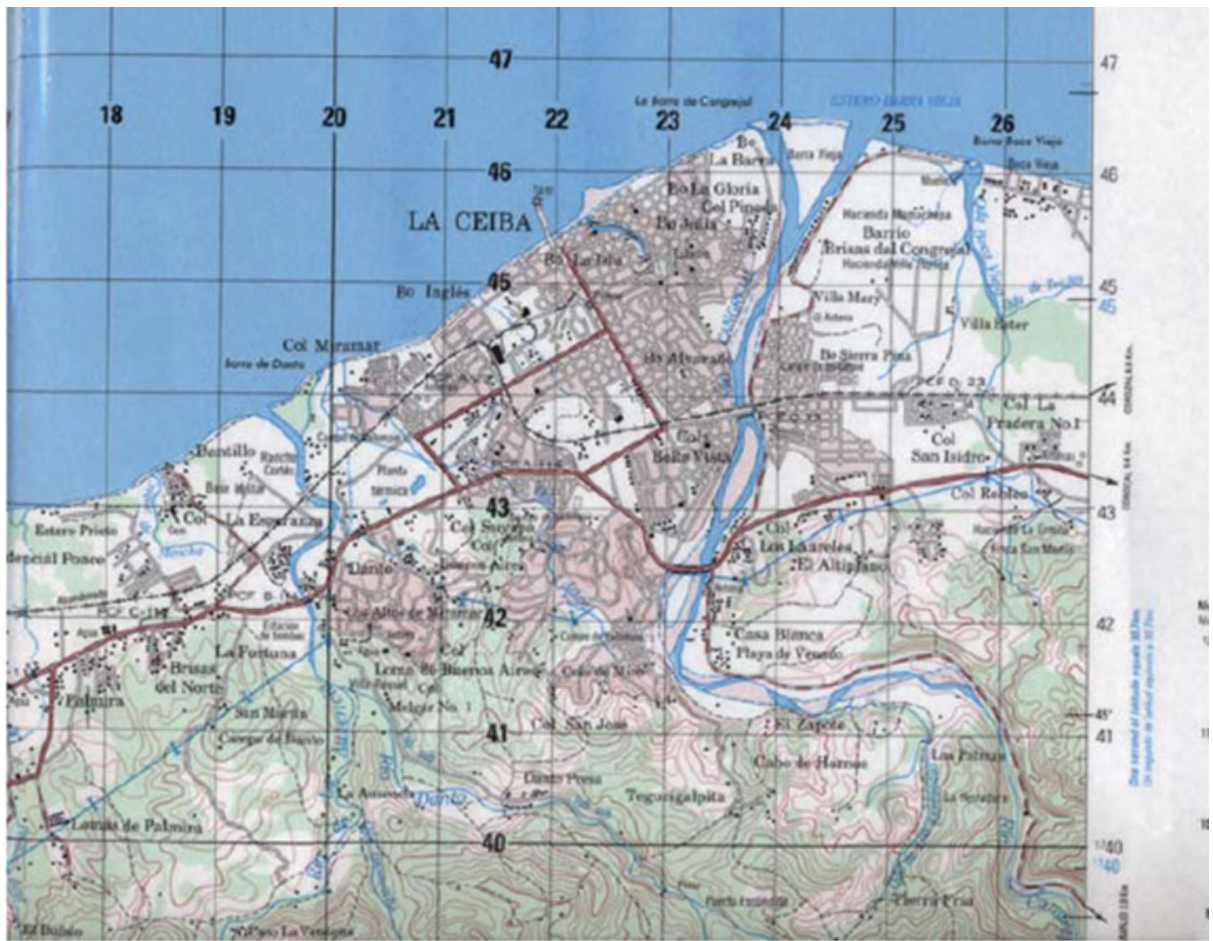

Fig. 2 Map of La Ceiba. The Rio Cangrejal is east of the city and the Rio Danto is just west of the city. The Rio Bonito is farther west and is not displayed on the map. Source: Cardini and Richards 2005

water and sanitation, health, disaster preparedness, democratic strengthening, microenterprise development, natural resources management, and agricultural diversification.

\subsection{Scoping risks from climate change}

This study of vulnerability and adaptation options for La Ceiba applied a method developed for the USAID for examining how development projects can incorporate climate change risks. The method relies on working closely with stakeholders to identify vulnerabilities and possible adaptations and select adaptations based on analysis (Furlow et al. This Issue). Using the method, we worked with stakeholders in La Ceiba to identify their concerns about current climate risks that might be exacerbated by climate change. We then analyzed how climate change could affect those risks and the costs and effectiveness of selected adaptation options. We next met with the stakeholders to present results of our analysis, and they set priorities about which adaptations they most desired.

We organized a workshop with a dozen local stakeholders from the federal government, the municipal government, the business community, nongovernmental organizations (NGOs), and the consulting community in La Ceiba on June 20-21, 2005, to discuss the parameters of an assessment of vulnerability and adaptation of La Ceiba to current climate and climate change.

The stakeholders expressed concern about such climate change risks as routine flooding of La Ceiba, flooding of the Rio Cangrejal from extreme precipitation events, flooding from 
hurricanes, and droughts. The stakeholders agreed that climate change could be a serious additional risk to La Ceiba. They agreed that a study of risks to current climate and climate change should address coastal resources, flooding from the Rio Cangrejal, and urban drainage. The stakeholders asked that the study focus on downtown La Ceiba, an area known as Barrio La Isla. They also asked that the study consider potential climate impacts as far west as the Rio Bonito. The study would look at climate risks approximately 50 years from now.

The stakeholders attending the first workshop did not identify specific adaptation measures but asked that an analysis be done on a number of topics and that the analysis make recommendations on appropriate adaptation options to climate variability and change. The stakeholders asked that the following areas for adaptation be addressed:

- Coastal development

- Urban drainage

- Upstream land management.

The stakeholders also asked that the analysis of adaptations recognize the importance of:

- Promoting economic development

- Protecting the environment

- Protecting lives and property.

\section{Analysis}

We conducted research in three areas:

1. Climate change scenarios

2. Coastal resources

3. Flooding from the rivers and drainage.

These areas are described in the following paragraphs.

\subsection{Climate change scenarios}

The projected climate change scenarios in this analysis focus on sea level rise and increases in intensities of hurricanes and extreme precipitation events (results are summarized in Table 1). We used the scenario-generating tool MAGICC/SCENGEN (Wigley et al. 2009) to estimate changes in average monthly temperature along the north coast of Honduras. MAGICC/SCENGEN calculates average changes in monthly temperatures and precipitation relative to changes in global mean temperature from general circulation models (GCMs). Users select parameters to estimate change in global mean temperature. That change is multiplied by the regional scaler to yield estimated changes in monthly temperature and precipitation in selected regions. Using MAGICC/SCENGEN, we estimated that compared to 1990 climate, temperatures in Honduras will rise about $0.5^{\circ} \mathrm{C}$ by 2025 and roughly $1^{\circ}$ to $2^{\circ} \mathrm{C}$ by 2050 .

Based on the increase in temperatures, the scenarios also address how precipitation intensity and hurricane intensity could change. Trenberth et al. (2003) state that precipitation intensity will increase $7 \%$ for each $1{ }^{\circ} \mathrm{C}$ increase in mean monthly air temperature (this is the Clausis-Clapeyron relationship; see also Pall et al. 2007). Note that 
Table 1 Scenarios used in La Ceiba analysis. Changes are relative to 1990

Low Middle High

Sea level rise $(\mathrm{cm})$

2025

4

15

20

2050

6

20

60

Temperature $\left({ }^{\circ} \mathrm{C}\right)$

2025

0.3

0.5

0.6

2050

0.8

1.5

Increased precipitation intensity (in intense rain events;\%)

2025

2050

2

4

Increased maximum wind speed (\%) in hurricanes

2025

2050

23

3

4

3

6

Increased precipitation (\% within $100 \mathrm{~km}$ of center) from hurricanes

2025

6

9

10

2050

8

17

25

the increase in extreme precipitation is larger than projected increases in average precipitation, which is 1 to $2 \%$ per ${ }^{\circ} \mathrm{C}$ (Trenberth et al. 2003). To estimate changes in extreme precipitation, we multiplied estimated increases in average monthly temperatures by $7 \%$. We assume this increase of $7 \%$ per ${ }^{\circ} \mathrm{C}$ increase in temperature applies only to the most intense precipitation events, such as those that produce flooding in the Rio Cangrejal.

We applied Knutson and Tuleya's (2004) results to estimate change in the intensity of hurricanes. Knutson and Tuleya examined model estimates of the change in hurricane intensity over an 80-year period. They estimated that sea surface temperature (SST) in three areas of cyclogenesis (Atlantic Basin, northeast Pacific, and northwest Pacific) would increase 0.8 to $2.4^{\circ} \mathrm{C}$. This causes a $14 \%$ decrease in central pressure, a $6 \%$ increase in wind speed, and an $18 \%$ increase in precipitation. There is substantial variation in projected changes in hurricane intensity across models. Assuming an average change in SST of $1.6^{\circ} \mathrm{C}$, central pressure decreases $8.75 \%$ per ${ }^{\circ} \mathrm{C}$, wind speed increases $3.75 \%$ per ${ }^{\circ} \mathrm{C}$, and precipitation increases $11.25 \%$ per ${ }^{\circ} \mathrm{C}$. These average estimated changes in wind speed and precipitation in hurricanes were applied in this study.

We used these scaling factors to estimate how hurricane intensity in the Caribbean could increase. We used the MAGICC/SCENGEN model to estimate monthly temperature increases in an area of the Atlantic Basin specified by Knutson and Tuleya (2004) (approximately 10 to $25^{\circ} \mathrm{N}$ by 50 to $80^{\circ} \mathrm{W}$ ) where hurricanes tend to strengthen. Knutson and Tuleya (2005) state that the average increase in SST is $1.75^{\circ} \mathrm{C}$. We scaled the changes in hurricane intensity by dividing average SST changes for the Atlantic Basin by 1.75 and then multiplying that figure by the scaling factors listed above to yield changes in central pressure, wind speed, and precipitation.

To estimate a range of potential changes in temperature in the Caribbean, we used MAGICC/SCENGEN. We selected 13 GCMs that best simulate current temperatures in the region and around the globe. To reflect a range of potential changes in greenhouse gas (GHG) emissions, we used the B1, A1B, and A1FI emissions scenarios (Nakićenovic et al. 2000). In 2025, the carbon dioxide $\left(\mathrm{CO}_{2}\right)$ concentrations from these scenarios differed little. 
Consequently, we used the A1B scenario. By 2050, the estimated $\mathrm{CO}_{2}$ concentrations differed enough to justify using all three scenarios. We used climate sensitivities of $1.5,3.0$, and $4.5^{\circ} \mathrm{C}$ for $\mathrm{CO}_{2}$ doubling (Solomon et al. 2007). We developed combinations of GHG emissions scenarios and climate sensitivities to capture a wide range of potential temperature changes. These scenarios were organized into low, middle, and high scenarios for 2025 and very low, low, middle, high, and very high scenarios for 2050. We ran each scenario using the 13 selected GCMs in SCENGEN and estimated model average temperature increases in the peak precipitation and hurricane months of July through November.

We estimated that storm surges in a repeat of a Hurricane Fifi would increase by about 0.3 to $0.6 \mathrm{~m}$ ( 1 to $2 \mathrm{ft}$ ). Sea level rise projections show a rise in the region of 5 to $20 \mathrm{~cm}$ by 2025 and up to $60 \mathrm{~cm}$ by 2050 (with middle estimates of $12 \mathrm{~cm}$ by 2025 and $20 \mathrm{~cm}$ by 2050; Cardini and Richards 2005). The increase in storm surge only accounts for higher sea levels and not stronger wind speeds, which also increase storm surge.

\subsection{Coastal resources}

The largest area at risk of inundation from sea level rise and coastal storms is the area between Rios Danto and Bonito, i.e., the area west of downtown that is currently less developed (see Fig. 3; area shown in red). Also, an area near the port, east of the Rio Cangrejal, is at risk for coastal flooding. When current populations are examined, the area with the most people at risk from coastal flooding is the area in downtown La Ceiba where the Malecon project was being planned. This project, supported by the World Bank, is intended to generate tourism by building large jetties to accumulate sand and enlarge the beach; a boardwalk would then be built with kiosks added to the new beach areas.

We also examined a projected population growth of $4 \%$ per year for La Ceiba, which is an extrapolation of current trends. Most of the development would occur between Rios Bonito and Danto. When population growth is taken into account, the greatest risks to inhabitants from the increased coastal flooding is still the area between the Rios Danto and Bonito. Additional risks presented by climate change are relatively small in 2025 but increase substantially by 2050 .

We examined the following adaptation options:

1. Protect natural defenses of the coast such as sand dunes and vegetation. These measures are the least intrusive and best protect the natural environment.

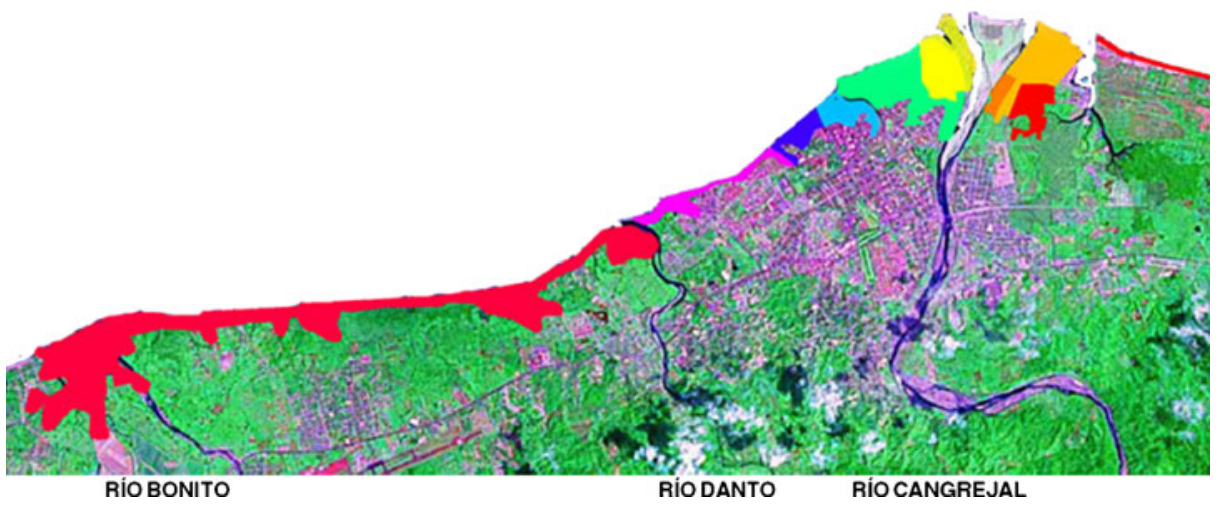

Fig. 3 Area on La Ceiba's coast at risk from a 3-m storm surge 
2. Limit development close to the coast in undeveloped areas and relocate infrastructure as necessary. It seems reasonable to limit development where, for the most part, it has not happened. However, we found in our visits that current rules limiting development were often ignored. Whether future development could be limited is in doubt.

3. Use soft defenses such as revegetation and sand pumping. These solutions can be costly because they need periodic maintenance. However, they are more sustainable and preferable to hard defenses.

4. Use hard defenses such as breakwaters or sea walls. Build breakwaters (above the surface or submerged) to provide some protection against storm surge and erosion. The hard defenses are least desirable because they can disrupt the natural flow of sediments and the defenses themselves can become eroded.

In general, sand pumping or the building of groins or breakwaters alone would not solve coastal erosion problems, but a combination of groins and pumping could maintain La Ceiba's beaches.

To study the different alternatives, the following procedures were applied:

- We evaluated the wave climate in deep water using a series of 3-hour data for 8 years, generated by the Wavewatch III model developed by the National Oceanographic and Atmospheric Administration (NOAA). We translated the wave statistics from deep water to the coastal area using the STWAVE model (STeady State Spectral WAVE USACE) estimation of wave climate statistic and extreme conditions related with normal storms from the north and from hurricanes.

- We evaluated coastline erosion using the SBEACH model (Storm Induced BEAch Change, USACE) for different scenarios of sea level rise and extreme wave conditions. We checked results using the "Bruun Rule" (Bruun 1998) for shoreline retreat. The coastline regression was calculated to about 20 to $30 \mathrm{~m}$ for a mean sea level rise of $0.5 \mathrm{~m}$ in 100 years.

- We then analyzed different alternatives of shoreline protection using the GENESIS model (GENEralized model for SImulating Shoreline change; Hanson and Kraus 1991), with the objective of compensating for the shoreline regression. Calculations of littoral transport and sand balance in the coastal area of La Ceiba and the Rio Cangrejal were made.

The alternatives simulated with the model were:

1. Small groins perpendicular to the beach with sand fill of $25 \mathrm{~m}$ to compensate for the coastline regression during storms.

2. Offshore breakwaters, parallel to the beach.

3. Offshore sills (submerged breakwaters), parallel to the beach.

The first option was selected because the offshore structures tend to generate a strong coastal advance ("perched beach," or "tombolo") and have higher costs because the rock volume is important and the construction methodology is complex (i.e., equipment is required to place the rocks into the sea far from the coast).

\subsection{Flooding and drainage}

We estimated runoff in the Rio Cangrejal during Hurricane Mitch and the 50-year rainfall events (i.e., an event that is likely to happen once in 50 years, or has a 1 in 
50 chance of happening in any year). The latter are the result of frontal storm systems, not hurricanes. This proved to be a challenging exercise because daily precipitation data were not readily available. It was difficult to determine if proper procedures were used to measure precipitation and flow of the river, especially during severe storms.

We analyzed the hydraulic implications of current extreme flows and potential increases resulting from climate change. For this analysis we followed standard Federal Emergency Management Agency (FEMA) and engineering hydrology practices. We first developed a hydrologic model of the catchment to establish a design storm and then ran the model with the design storm (Bedient et al. 2008).

A hydrologic rainfall runoff model was developed for the catchment. Using HEC-GeoRas (USACE 2000), a 90-m digital elevation model of Honduras was used by GeoHMS to delineate the sub-catchments. The basin was divided into five sub-catchments. We used GeoHMS to calculate basin topographic characteristics; together with local soil data, the rainfall runoff model was developed.

A 50-year design storm was established for the entire catchment. A spatially explicit 50-year, 24-hour design rainfall was developed by Mastin (2002). The isohyets were input into ARCGIS, and spatially averaged, 24-hour 50-year precipitation values were estimated for the five sub-catchments, with values ranging from $225 \mathrm{~mm}$ to $400 \mathrm{~mm}$ per day. See Fig. 4.

This 50-year design storm was for current climate. The 24-hour design storm or storm intensity was adjusted based on Trenberth et al. (2003; see above).

The historical and climate changed 24-hour 50-year design storms were simulated with the HEC-HMS model, and peak discharges for La Ceiba were calculated. The historic data were compared with U.S. Geological Survey (USGS) regression-based peak flows and

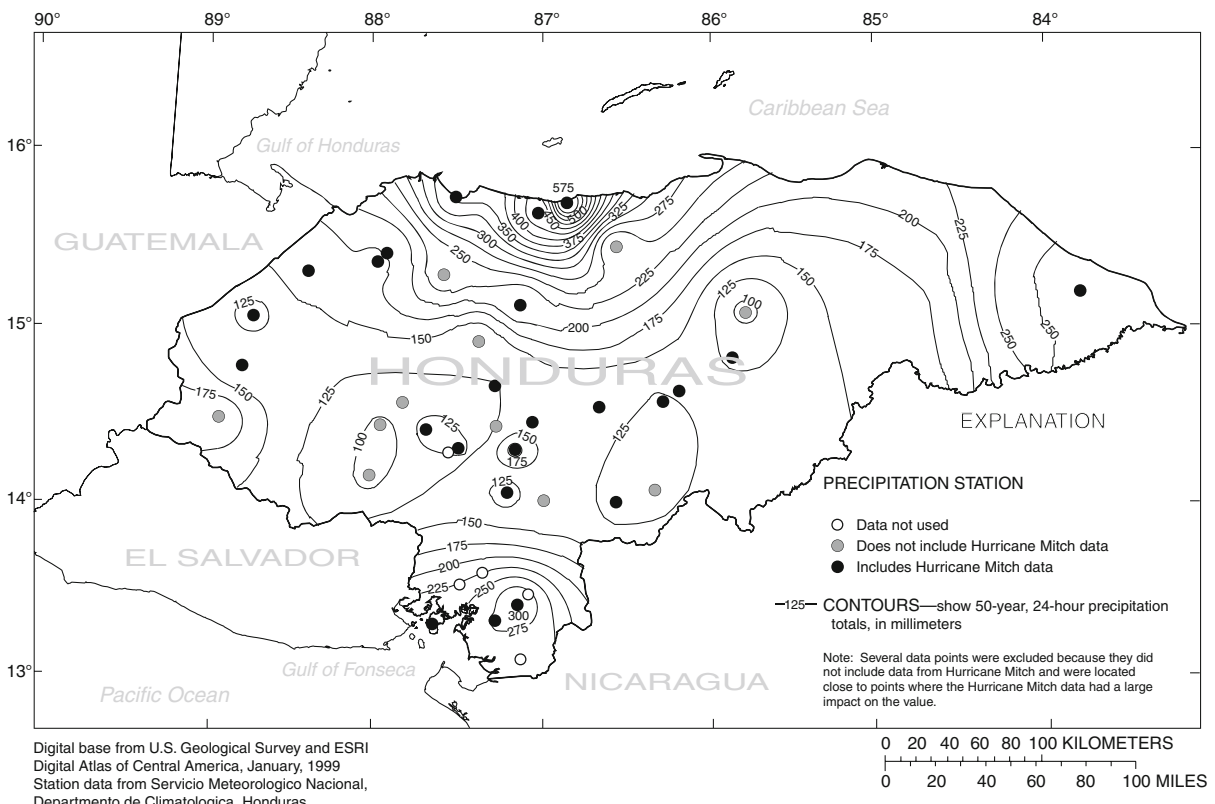

Fig. 4 Isohyets for 50-year design storm (Mastin 2002) 
found to be twice as high (Kresch et al. 2002) due to the very unique conditions of tropical storm conditions on a very steep coastal mountain range.

The team then used the HEC-GeoRAS model (USACE 2000), as used by Kresch et al. (2002), to estimate the flood stage (elevation) for each peak discharge from the hydrologic modeling. Flood plain maps were generated automatically with HEC-GeoRAS.

The current levees are too low to protect against flooding at peak flow from a hurricane of Mitch's intensity ${ }^{1}$ and are inadequate to handle the current 50 -year runoff. The floodwaters would overtop the levees, which implies that the levees may be under-designed for peak flows.

When climate change is added to current extreme precipitation events, the current levees are even less adequate to protect La Ceiba. An additional 5\% precipitation during intense storms would breach the levees close to the Barrio La Isla (in downtown La Ceiba).

The levees also appear to be inadequate to cope with the higher flow from a climate change-enhanced hurricane. One problem with hurricanes is that storm surge would block runoff and force the Rio Cangrejal into La Ceiba. The existing levees are inadequate to protect La Ceiba from the combined effects of a storm surge and high river flow during hurricanes. The higher storm surge and higher river flow worsen the problem.

Raising levees 1 to $2 \mathrm{~m}$ would provide sufficient protection from a climate changeenhanced 50-year storm. Figure 5 displays the levee heights needed to protect La Ceiba against the current and climate change-enhanced 50-year storms. Our preliminary cost estimate for raising the levees is between $\$ 750,000$ and $\$ 1.2$ million. There are also two other possible adaptations. One involves lining the lower Rio Cangrejal with concrete, which "speeds" the flow of water and lowers the height of the river. That option, however, would costs tens of millions of dollars, cause environmental damage, and could be visually unattractive. The second option involves rehabilitating blocked natural drainages in La Ceiba or east of the Rio Cangrejal to divert high flows. This would require removing existing structures and digging out old channels. We estimate that the cost of rehabilitating the blocked drainages is between $\$ 750,000$ and $\$ 1.5$ million.

Protecting La Ceiba from the combined effects of storm surge and high flow is difficult. The only solution would be to build a sea wall high enough to stop the storm surge and to install pumps to remove water out of La Ceiba.

A hydropower dam on the Rio Cangrejal is being considered, but this appears to provide little potential to reduce flooding. A flood control dam would probably need to be built farther upstream. To be sure, there would be many trade-offs with such a dam, since it could displace many residents in the watershed. In addition, it could trap sediments that are needed to replenish La Ceiba's beaches.

We also analyzed options for addressing drainage problems in La Ceiba. We examined installing a subterranean drainage system to collect and dispose of runoff during storms sufficient to cope with storms that currently happen once in 5 years. Pumps may be needed to evacuate water from the city. A storm gate may be needed to protect the city from inflow of water during hurricane storm surges. We estimate the cost of installing such a system to be about $\$ 1.7$ million. To adequately handle the estimated increase in peak flow, larger pipes would be needed, which would raise the cost by $\$ 600,000$ or about one-third.

\footnotetext{
${ }^{1}$ In addition, sustained high runoff of Mitch's intensity over several days could erode infrastructure such as levees and bridges.
} 


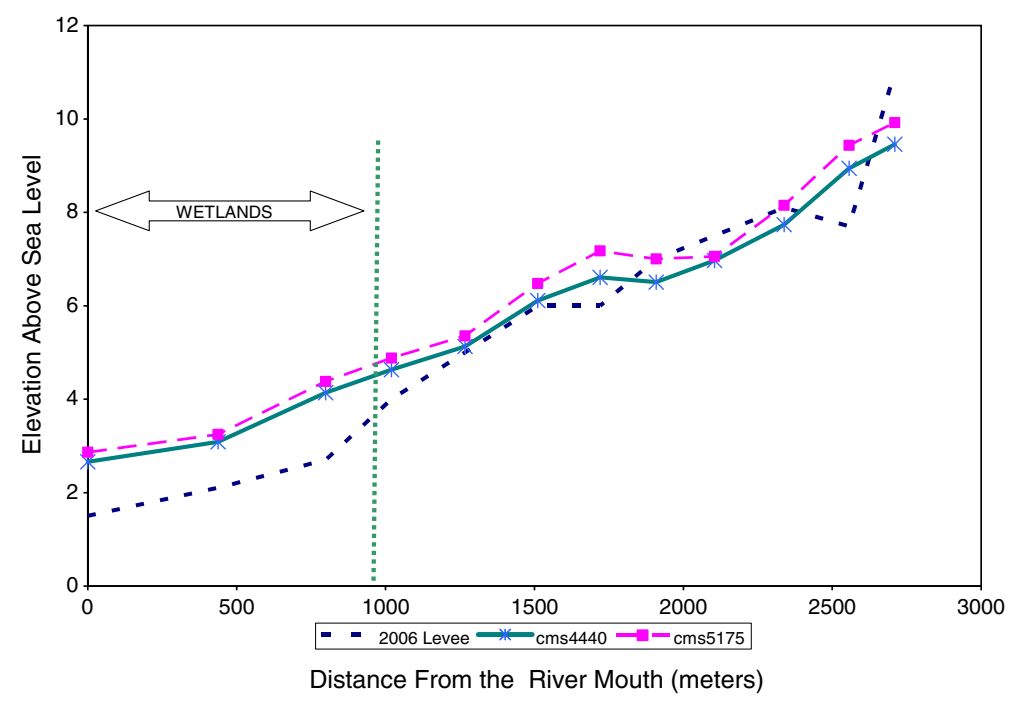

Fig. 5 Levee heights needed for current 50-year storm and 13\% increase in 50-year storm

\section{Stakeholder consideration of adaptation options}

A second workshop with La Ceiba stakeholders was held June 22, 2006, to present the analysis and discuss adaptations. This included municipal workers and NGOs. We also met with the mayor and the Municipal Corporation (La Cieba's city council, composed of half a dozen vice-mayors).

Following presentation of the analysis, the stakeholders identified the adaptations listed in Table 2 as being feasible. The adaptations listed in regular font are those that were identified as part of the analyses conducted for the project. The adaptations that are crossed out were analyzed as part of the project and were rejected by the stakeholders. Both adaptations rejected by the stakeholders - building a sea wall and lining the river-appear to have been rejected because they are not aesthetically appealing. This is consistent with La Ceiba's desire to increase tourism because such infrastructure could make the city unattractive.

The adaptations in italics are those proposed by the stakeholders. They are nonstructural solutions, including improving environmental awareness, enhancing the existing flood warning system, and limiting deforestation (and promoting reforestation). The latter option could substantially reduce peak flows in the Rio Cangrejal and other basins vulnerable to extreme precipitation.

The stakeholders seemed to prefer addressing urban drainage rather than the Rio Cangrejal flooding and coastal area protection. This may be because urban flooding is a frequent problem and may be an impediment to economic development.

The mayor and the Municipal Corporation discussed fundamental questions about priorities for La Ceiba. For example, they wondered if the most vulnerable areas should be protected or if the emphasis should be on economic growth. Some promoted expansion of the coastal areas. The controversial proposed hydropower dam on the Cangrejal was discussed. The analysts pointed out that the dam would trap sediments, depriving the beaches of sediment and leading to erosion. They also said that the proposed dam would be inadequate to prevent flooding from hurricanes and severe storms. 
Table 2 Identified adaptations

Risk management

Decide what level of risk is appropriate

Zoning

Environmental education

\section{Coastal zone}

\section{Developed areas (Cangrejal to Danto)}

Groins

Sand pumping

Breakwaters

Submerged breakwaters

[Sea wall]

Renewal/accommodation

\section{Less developed areas (Danto to Bonito)}

Set-backs

Zoning and building codes

Accommodation (e.g., houses on stilts)

\section{Rio Cangrejal flooding}

Improved design and higher levees in most vulnerable locations

Flood channel - could be expensive; need to analyze alternative locations

[Lining of river ehannel]

Limit deforestation; promote reforestation

Dam - if it provides flood control

Dredging of river

Flood warning system

\section{Urban drainage}

Accommodate flooding (adapt to flooding that happens)

Install drainage systems

Collectors

Retention

Storm gate

Pumps 


\section{Conclusion}

La Ceiba, Honduras, is already quite exposed and vulnerable to climate variability. Lying in an alluvial floodplain between the Caribbean sea and the 8,000-foot Nombre de Dios mountains, and with the Rio Cangrejal flowing at its edge, the city is vulnerable to flooding from the river and from coastal storms. Climate change will likely increase the city's vulnerability through sea level rise, more coastal storms, and more intense flooding of the Cangrejal.

Working with stakeholders in the city, the team of authors identified the concerns stakeholders have about vulnerability to current climate and climate change and the options for adaptation. These options were assessed and presented to stakeholders. The stakeholders preferred addressing routine flooding of the city through installation of an urban drainage system rather than through measures to control less frequent but more severe flooding. They emphasized improved management of the watershed of the Rio Cangrejal and improved warnings of imminent storms to cope with risks from extreme precipitation and cyclones. Adoption of risk management principles and effective land use management could also help reduce risks from current climate and climate change. The stakeholders also preferred relatively unobtrusive measures to protect the coastline from sea level rise and more intense storms such as groins and sand pumping, rather than sea walls.

This project demonstrates that the approach discussed in Furlow et al. (this issue) can be applied to assess vulnerability to climate change and select adaptations to reduce those vulnerabilities.

\section{References}

Bedient PB, Huber WC, Vieux BE (2008) Hydrology and Flood Plain Analysis, 4th edn. Prentice Hall, Upper Saddle River

Bruun P (1998) The Bruun rule for erosion by sea-level rise. Journal of Coastal Research 4(4)

Cardini J, Richards J (2005) La Ceiba, Honduras Trip Report. Memorandum to Duane Muller, Jonathan Padgham, and Peter Hearne, U.S. Agency for International Development, from Julio Cardini and Julie Richards, Consultants to Stratus Consulting Inc, Boulder

Furlow J, Smith JB Anderson G, Breed B, Padgham J (This Issue) Introduction to Climatic Change Special Issue. Climatic Change.

Gurteen Knowledge Website (2006) Map of Honduras. Available: http://www.gurteen.com/gurteen/gurteen. nsf/id/L000185/\$File/ho-map.gif. Accessed July 21, 2006.

Hanson H, Kraus N (1991) GENESIS. Generalized Model for Simultating Shoreline Change; Report 1, Technical Reference and Report 2, Workbook and System User's Manual. CERC-89-19. Department of the Army, Waterways Experiment Station, Corps of Engineers.

Knutson TR, Tuleya RE (2004) Impact of $\mathrm{CO}_{2}$-induced warming on simulated hurricane intensity and precipitation: Sensitivity to the choice of climate model and convective parameterization. J Clim 17:3477-3495

Knutson TR, Tuleya RE (2005) Reply. J Clim 18(23):5183-5187

Kresch DL, Mastin MC, Olsen TD (2002) Fifty-year Flood-inundation Maps for La Ceiba, Honduras. U.S. Geological Survey Open-File Report 02-254.

Mastin, MC (2002) Flood-hazard Mapping in Honduras in Response to Hurricane Mitch. U.S. Geological Survey Water-Resources Investigations 01-4277.

Merrill TM (ed.) (1995) Honduras: A Country Study. U.S. Library of Congress, Washington DC. Available: http://lcweb2.loc.gov/cgi-bin/query/r?frd/cstdy:@field(DOCID+hn0024).

Nakićenovic NJ et al (2000) Emissions Scenarios. A Special Report of Working Group III of the Intergovernmental Panel on Climate Change. Cambridge University Press, New York

Pall P, Allen MR, Stone DA (2007) Testing the Clausius-Clapeyron constraint on changes in extreme precipitation under $\mathrm{CO}_{2}$ warming. Clim Dyn 28:351-363 
Solomon SD et al (eds) (2007) Climate Change 2007: The Physical Science Basis. Contribution of Working Group I to the Fourth Assessment Report of the Intergovernmental Panel on Climate Change. Cambridge University Press, New York

Trenberth KE, Dai A, Rasmussen RM, Parsons DB (2003) The changing character of precipitation. Bull Am Meteorol Soc 84:1205-1217

USACE (2000) HEC-GeoRas. An Extension for Using ArcView User's Manual. U.S. Army Corps of Engineers. Hydrologic Engineering Center, Davis

Wigley TML et al (2009) Uncertainties in climate stabilization. Climatic Change 97:85-121

WRI (2005). Income and Poverty 2005. World Resources Institute, Washington, DC. Available: http:// earthtrends.wri.org/datatables/index.php?theme $=4$. 